\title{
The My Health Record (MyHR) Adoption in General Practices: Literature Review and Future Research Direction
}

\author{
Urooj Raza Khan ${ }^{1}$, Tanveer A Zia ${ }^{1,2}$, Chris Pearce ${ }^{4}$ \& Kaushalya Perera ${ }^{1,3}$ \\ ${ }^{1}$ School of Computing and Mathematics, Charles Sturt University \\ Locked Bag 588 \\ Wagga Wagga NSW 2678 Australia \\ E-mail:1urazakhan@.csu.edu.au,2tzia@.csu.edu.au, ${ }^{3}$ kush.perera12@gmail.com \\ ${ }^{4}$ The University of Melbourne \\ Victoria 3010 Australia \\ E-mail: drchrispearce@mac.com
}

\begin{abstract}
Digital health has significant potential in health and healthcare system improvement. My Health Record (MyHR), one of digital health solutions, has been one of the focus in Australia for past few years. Aiming to initiate a study of MyHR adoption in general practices, this paper brings up results of systematically reviewed literature. Four phased tool supported approach was employed and thematic analysis was conducted to describe the findings of the review. Three main themes were identified, focusing on MyHR system design/developments, its change management and evaluation. Evaluation was detailed further into eight sub themes related to MyHR intentions and outcomes, workflow conundrum, usability and effectiveness, awareness and knowledge, personal control, ethical considerations, impact of policy and economics and MyHR comparison worldwide. The literature drew a holistic picture about MyHR system and its adoption. There is some knowledge about the impacts of MyHR in the moral orders of the medical practices but the details and extent of this impact on general practices with this integration is noted as a gap hence, setting direction for future research.
\end{abstract}

Keywords: My Health Record, MyHR, PCEHR, General Practice, Digital Health

\section{Introduction.}

Digital health $(\mathrm{DH})$ is widely believed to have vast potential in offering solutions for improving health and healthcare delivery influencing: effectiveness, efficiency, accessibility, safety, and personalization [1]. It is the need of changing patient demographics, financial strictures, workforce shortages, health service provisions, advancement in medical technologies and their impact on healthcare delivery, that is driving $\mathrm{DH}$ now extensively around the world, including Australia [2-4].

Considering a shared electronic health record (EHR) solution at the national level as fundamental to Australian digital health infrastructure [5-7], a personally-controlled electronic health record (PCEHR), now named as My Health Record (MyHR) was launched in July 2012 [7, 8]. The MyHR, is a hybrid health information system integrating web based Personal Health Records (PHR) with clinical EHR systems, enabling consumers and healthcare providers to access health summaries/records through a platform with shared responsibilities and mixed governance model [9].

The MyHR contains potentially information from multiple sources - including general practice, prescribing, hospital records and consumer generated information [8]. General Practitioners (GPs) are the gateway to the health system: they are the most consulted health services $[10,11]$ and play a vital role in providing health information to the MyHR. GPs were generally positive about this system that would facilitate their ability to communicate their patient information for better patient care. The challenge noted was the additional time required by GPs to participate [12].

General practice is generally characterized as a culturally complex and complicated environment, where 
any change is considered challenging [13]. After GPs computerised, the MyHR brought another change in the 'moral orders governing medical practices' [5] and 'traditional power structure' [8, 14, 15] with increased level of patient access and personal control rights. It is argued that the benefits gain and its realization should include the impact of the MyHR on the associated processes and work practices in addition to its influence on patient model-of-care $[5,16]$. There has been research around impact of MyHR on patient care [17, 18] but effects on the organizations itself due to this system integration is not adequately investigated.

Hence, the aim of this research is to investigate MyHR adoption in general practices (Victoria) and explore the impact of its integration on their work practices and patient workflow. This paper offers a summary of the literature reviewed to understand the extent of existing research in this context and identifies gaps to set future research direction.

\section{Method}

This literature review adopted a structured and systematic approach, four-phased tool supported approach [19] using EndNote and Nvivo (Figure 1).

In the first phase, a pool of relevant papers was extracted (in May 2016) from 10 journal databases:
Medline, Cinahl, Embass, PubMed, IEEE, Web of Science, Scopus, Informit, ProQuest and Ebsco. The search was limited to English language-based peer reviewed journal articles and conference proceedings for the past 5 years using the terms: (PCEHR OR 'personally controlled electronic health record') OR ((myhr OR 'My Health Record') AND Australia) OR ((ehr OR 'Electronic Health Records') AND Australia). This search resulted in 487 relevant journal articles (Figure 2).

During the second phase, articles were screened to find duplicates, narrowing down the results to 282 . These abstracts were reviewed, filtering 126 articles as 'relevant' based on positive response to ANY of these three questions: (a) Is it about the national EHR system, MyHR or PCEHR [Y1]? (b) Is it referencing MyHR and general practice [Y2-GP] or any secondary field [Y2]? (c) Is there any MyHR connection or comparison internationally [Y3]? If all the answers were No, those abstracts were excluded.

In the third phase, 126 articles were read in full, narrowing the list to 93 as 'most-relevant' based on the above revised answers of the above 3 questions. Out of the 93 items, there were 21 research papers, others were literature reviews, opinions, magazine articles, electronic book sections and conference proceedings.

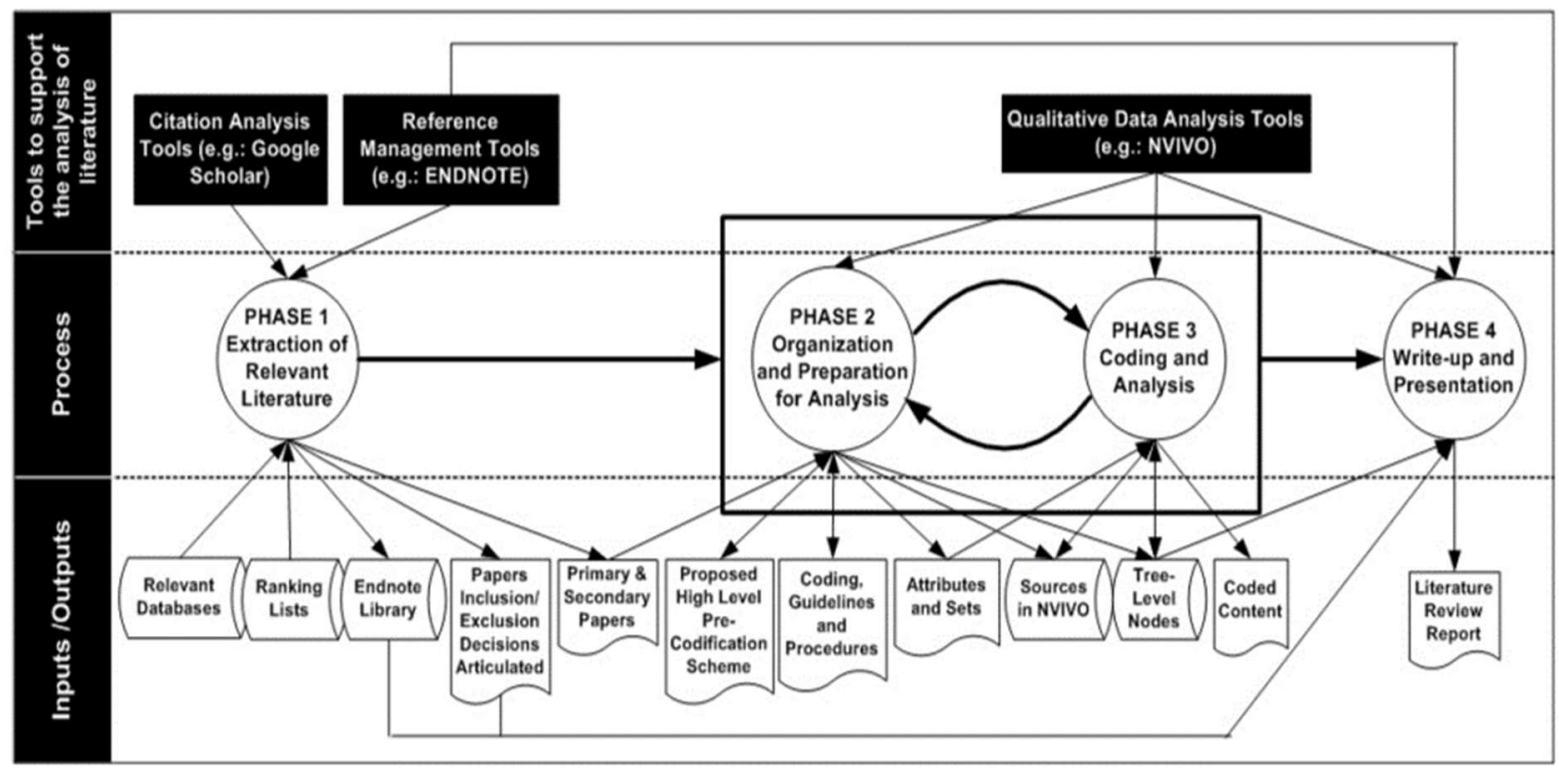

Figure 1 - Overview of literature review approach [19] 


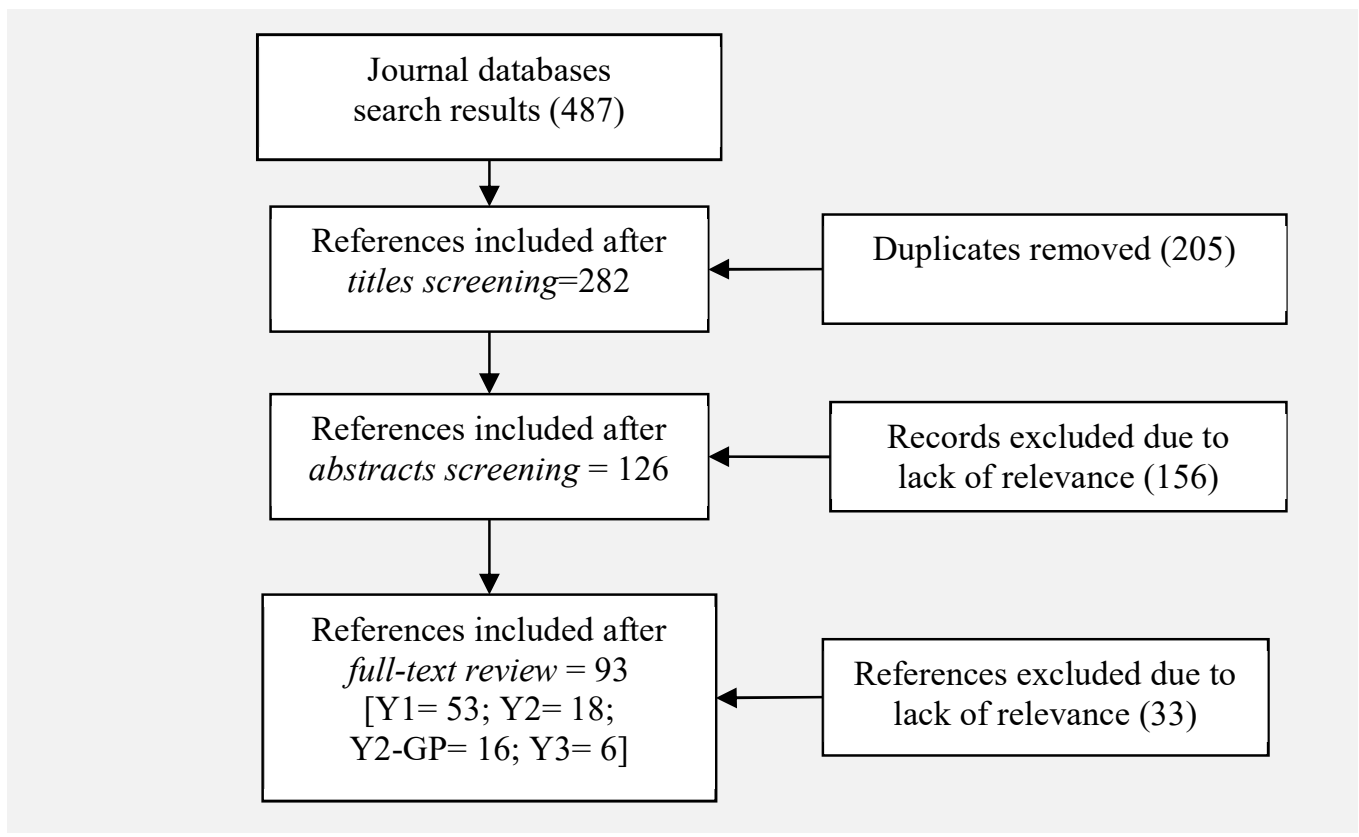

Figure 2: Filter flow diagram of the literature review

More material was also extracted within the 93 articles using snowballing and expert referencing techniques. During analysis, nodes were defined as the most frequently appeared topics were encountered. These nodes were refined as reading progressed and later used as themes with insights documented in the final phase.

\section{Findings and Discussion}

The findings related to general practice usage of MyHR were very limited (3.3.2), however, it demonstrated a good holistic picture of MyHR implementation and adoption issues in general. Three main themes and eight subthemes were identified from the collected literature, described and summarized in table 1:

\subsection{MyHR System Design and Developments}

MyHR was designed to be a distributed system that delivers a central infrastructure with several repositories to manage the location and transfer of health information. Commenced with opt-in approach for consumers and health providers, it was not meant to be a replacement for existing clinical information system (CIS) instead a supplementary source of information $[8,16,20,21]$.

Two main types of users noted were consumers (Australian citizens) and healthcare providers (hospitals and general practices). Input to the system goes by these users through different types of documents at various stages of patient care cycle. A shared health summary (SHS), a fixed in time document, was to be created by the GP during patient consultation, with summary details to assist in treatment by other providers. Medicare was also another source of information providing access to Medicare claims data [8, 22-24].

Consumers access MyHR using the consumer portal to view, input data, set access control levels and monitor audit $\operatorname{logs}[8,15,22,25]$ whereas healthcare providers use the MyHR through their CIS, or a provider portal (read only) $[8,26]$. To access the MyHR system, healthcare provider organizations needed their health provider identifier-organization (HPI-O) [27], National authentication service for health public key infrastructure, a conformant CIS [28], MyHR participation agreement [29], MyHR organizational policies and MyHR assisted registration policy [16, 27].

The knowledge captured in this literature review was based on the functionality of the system based on the 2012 release. There were references to the possible functionalities of future releases such as increasing the focus on delivering consumer benefits and improving on system maturity [8]. There was work-in-progress on the workflow/practices details in relation to pathology and radiology results [30]. However, there was no clear description of how and when it would be done. There was also mention about a MyHR review conducted by the government to examine any associated issues [26] resulting in PCEHR rebranding and opt-out trials. 
Table 1: Summary of Literature Review Findings

\begin{tabular}{|c|c|}
\hline 3.1. MYHR SYSTEM DESIGN AND DEVELOPMENTS & 3.2. CHANGE MANAGEMENT AND ADOPTION \\
\hline 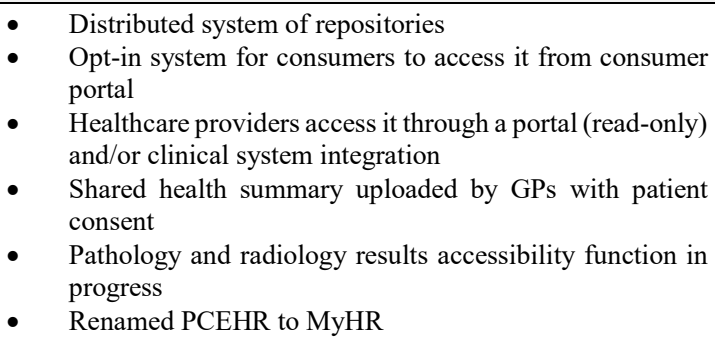 & 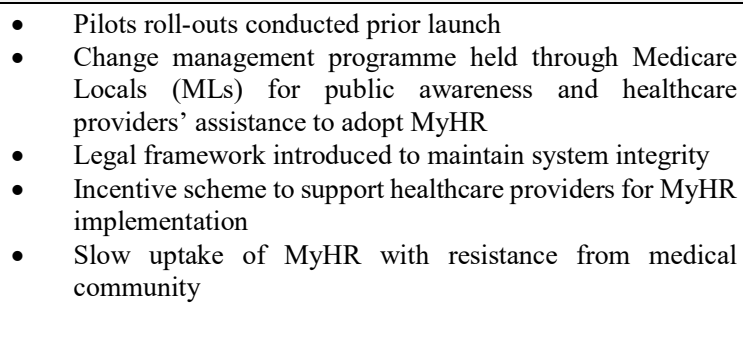 \\
\hline \multicolumn{2}{|l|}{ 3.3. EVALUATION } \\
\hline $\begin{array}{l}\text { 3.2.1. Intention and Outcomes } \\
\text { - Literature abundant with theoretical benefits that seem } \\
\text { difficult to achieve and realise. } \\
\text { - } \text { Outcome revealed slow adoption of MyHR generally. } \\
\text { - Adoption of MyHR in general practice is little known. } \\
\text { 3.3.3. Usability and Effectiveness Issues } \\
\text { - MyHR usability issues highlighted in some consumers- } \\
\text { based researches. } \\
\text { Healthcare providers' perspectives are least known but it } \\
\text { is realized that usability is a vital factor for successful } \\
\text { adoption. }\end{array}$ & $\begin{array}{l}\text { 3.3.2. Workflow/Benefit Conundrum } \\
\text { - } \quad \text { Adoption of MyHR require change in the existing patient } \\
\text { workflow for clinicians. } \\
\text { This change in practice require consultation time with no } \\
\text { apparent benefit. } \\
\text { Resulting lack of support from medical professionals. } \\
\text { 3.3.4. Personal Control } \\
\text { - MyHR gives personal control to consumers to opt-in and } \\
\text { decide their record access for better participation in health } \\
\text { management. } \\
\text { This is criticized by medical community and have raised } \\
\text { concerns about information completeness and accuracy. }\end{array}$ \\
\hline $\begin{array}{l}\text { 3.3.5. Awareness and knowledge } \\
\text { - Slow uptake of MyHR has been blamed to lack of } \\
\text { awareness in community. } \\
\text { - Limited knowledge in medical community about MyHR } \\
\text { has contributed in their resistance. }\end{array}$ & $\begin{array}{l}\text { 3.3.6. Ethical considerations } \\
\text { - Secondary-use/research of data in MyHR have raised } \\
\text { concerns about its ethics. } \\
\text { - These concerns remain overshadowed by business and } \\
\text { technical requirements for MyHR. }\end{array}$ \\
\hline $\begin{array}{l}\text { 3.3.7. Impact of Policy, Economic and Legislation } \\
\text { - Government policies uncertainties and unstable } \\
\text { commodity market are likely to impact this national } \\
\text { implementation and its funding. } \\
\text { Medico-legal risks and lack of professional indemnity } \\
\text { insurances related concerns in medical community. }\end{array}$ & $\begin{array}{l}\text { 3.3.8. MyHR Comparison Worldwide } \\
\text { - Three types of national implementations noted, top to } \\
\text { bottom (UK), bottom to top (US) and middle-out (Australia) } \\
4 \text { critical success factors identified when MyHR compared } \\
\text { with other similar national implementations. }\end{array}$ \\
\hline
\end{tabular}

\subsection{Change Management and Adoption}

Extensive planning and efforts were made to facilitate the MyHR change management with pilot roll outs [24, 27], a change and adoption programme [16], legal framework [7] and incentives (ePIP). General practices, in particular, was facilitated with ePIP to implement [16] and participate [31] in MyHR.

Independent of hospitals, GP readiness with DH in general and all the support provided [7], the MyHR experienced slow participation [22, 23, 32]. Consumers' participation was lower than expected in the first year [7, 28]. Despite $80 \%$ of general practitioners (GPs) signed up (prompted by the government incentives), less than $10 \%$ of GPs were noted in 2014 to be actively contributing to MyHR [26].

Although some believed that MyHR was a 'quiet revolution' in health record keeping and would build up steadily (like the discovery and invention of telephone) over time with benefits felt by consumers and healthcare professionals as the health records become well 'populated' [27]. The MyHR implementation generally faced criticisms [16] for its opt-in model, usability issues, privacy concerns, security risks [7] and public unawareness [33]. Concerns were also raised about

funding, fragmented governance of healthcare services, reluctance to change and adoption by healthcare professionals, lack of research evidence on the benefits, negative political influence and deficiency of appropriate policy models [7, 28].

\subsection{Evaluation of the System}

Initially research conducted was focused on the user expectations [34-36] and users' views/perspectives [22, $24,26,33,37-41]$. Later the emphasis diverted towards benefits realization in different contexts where MyHR was used as an intervention for health management [18, 42]. This section summarizes these evaluation outcomes, views and perspectives as a set of eight sub-themes:

\subsubsection{Intentions and Outcomes}

With the intention to centralize and enable access to fragmented medical records for Australian citizens, policy makers anticipated to deliver benefits of improvements in patient care, safety and cost through MyHR [15, 28, 43-45]. It was envisaged that such implementation would simplify the patient journey [28], increase patient engagement $[8,44]$, better policy and planning $[26,46]$, medical error reduction, improved 
health outcomes, contributing in efficient and effective health system [46]. Literature noted that record access to patient plays role in enhancing patient self-care, participation in care and quality of care [47]. Annual saving of $\$ 7$ billion in direct costs was estimated in return of digitizing the healthcare sector with substantial improvements in the customer experience by avoiding millions of hospital visits and admissions [32].

While literature seem abundant with theoretical and potential benefits of MyHR [48], the current state of MyHR emerged from the scope of this literature review, showed that achieving these benefits was difficult [28] and challenging to realize. The outcome of MyHR implementation indicated slow uptakes of the system with range of concerns and very limited research about benefits delivery, particularly true for MyHR in general practice context. In the early years, the research was focused on the anticipations [34-36], users views/perspectives [22, 24, 26, 33, 37-41] and now its moved towards benefits realization. Such benefits realizations research was put in specific context where MyHR was used as an intervention with citizens that were seniors and chronic patients $[18,42]$.

\subsubsection{Workflow/benefit Conundrum}

Gains and benefits appear with neither eHealth applications nor information, it comes from changing the process or working practices, as argued by [16]. Also, benefits can only be realized when the implications of MyHR interventions were measured, including not just on model of care but also on moral orders governing medical practices [5]. It was believed DH was more than technological battle, as it involved interdependent social interactions that were hardly predictable [28].

Health summary in MyHR was expected to be updated when patients visit their doctors/GPs. This was a change in patient workflow of general practice and influence pre-existing efforts (under Australian law) to the clinician's intellectual property. GPs were expected to fit in this change in their workflow when dealing with patients and raised concerns. Although this change brought information access to GPs, it required more consultation time of clinicians, incurring increase in cost [49]. The degree of change was also dependent on their CIS integration with MyHR. GP raised concerns about compensation of extra time consumed, and were advised to use existing reimbursement Medicare items [8]. Most of the GPs mostly work as contractor that means they were not remunerated by ePIP either [31]. This resulted resistance from medical community and did not gain enough support for MyHR usage. It was also reflected in a study where $95 \%$ of respondents mentioned they were not approached by their doctors to register with MyHR evening after six months of its implementation [34].
With the policy intervention that linked health summary uploads with ePIP, GPs needed to spend more time with patients to upload the summaries so that their practice could gain ePIP [31]. This was criticized by Australian Medical Council, advocates of MyHR, as not an appropriate approach for adoption, instead promoted the idea of Medicare based incentive payment for MyHR use [50].

\subsubsection{Usability and Effectiveness Issues}

Usability refer to the system being user-friendly and easy to use; effectiveness is when users are able to achieve the aimed objectives. These characteristics of usefulness are considered vital for the success of information systems, influencing directly on the usage behavior. Thus, a system perceived as easy to use and useful has better potential to be accepted and adopted $[35,38,51]$.

Since the launch, the MyHR was criticized about its usability and effectiveness, labelling it 'far from mature' [7]. A regional area focus group based study found that more work was needed on MyHR consumer portal to be 'user-friendly' in 2013 as the group faced issues like insufficient details, junk characters, language difficult to understand, long process to attempt a simple tasks and lack of any useful information [52]. Another survey research based findings suggested that consumers appreciated the value of MyHR but they did not believed it to be useful or compatible at the time of study [34]. Issues of utility and design also emerged inevitably in another study when participants were getting trained to use MyHR as part of chronic illness management program intervention in a rural community [42]. User friendliness issues were also encountered when seniors were engaged in workshops for better management of their health information in MyHR [18].

The attributes of usefulness of MyHR integration in CIS was also vital and limited relevant information was found in the scope of this literature review. A survey of 790 staff from 65 hospitals in Australia identified usability as significant factors in the use of eHealth/DH applications [53]. Clinicians must find this system useful for its diffusion and this was analyzed in a study of inhouse EHR system adoption, as an alternative to MyHR. The participants (GPs, specialists and administrative staff) perceived it useful and indicated that it was improving their 'quality of work, control over work, work more quickly, critical to the job, increase productivity, job performance, accomplish more work, effectiveness and makes job easier' [35]. In another study of interviews with GPs, it was learnt that their observation to MyHR integration with CIS was not found complicated but it was actually the change in the patient workflow and extra time involved [52]. 


\subsubsection{Personal Control}

Central to MyHR system features was the concept of patient-centered care [28], giving more personal control to consumers for better participation in health management and decision making, translating into better health outcomes [15]. It enabled them to opt-in, record their health details, include/exclude or even remove info, set access control for family and healthcare providers, had access to audit logs of who accessed their details and make enquires/complains about their information handling in MyHR [15, 54]. Thus, positioning consumers as owners of their health record, giving them more responsibilities and encouraging to actively engage in managing their health. Although consumers interest in taking this control was questioned by some [23], mostly consumer groups welcomed this approach [39]. Experts claims that it was patients' basic right to be able to have access control to their health information and also important for Australian Privacy principles compliance [40].

Increased level of patient rights and personal control brought some challenges, labelling it as 'significant shift in the moral orders' [5], change in 'traditional gatekeepers' [55] and 'traditional power structure' [8, 14, 15] of information in the healthcare sector, resulting far reaching implications for the rights and responsibilities of healthcare providers, patients and the State [5]. Healthcare providers raised concerns about MyHR optin approach [55], ability to hide information in health record $[7,46]$ and its accessibility [40].

(a) Opt-in Model. MyHR was launched with opt-in policy that allowed consumers to make an explicit decision to participate [7]. Slow adoption rate and review 2013 resulted in MyHR opt-out trails [50, $56]$ that means every individual with Medicare would have a health record in MyHR unless they specify not to participate [57]. It was believed that critical mass signups to system would result in more effective clinical use $[8,15,33]$ and better chances of consumer participation [44, 55]. However, there appears arguments that switching from opt-in to optout may not necessarily result in improved adoption rate $[42,58]$.

(b) Information Sharing. Healthcare providers feared that patients might not share the information that may be vital, impacting on the MyHR information completeness and accuracy [7]. However, according to a survey $56 \%$ consumers signed up for MyHR were willing to share their details with all the healthcare providers involved in their care, whereas remaining respondents were willing to share with some healthcare providers, GP (97\%), specialists (91\%), pharmacists (49\%), and dentists (38\%) [33]. Although consumers were expected to manage access control, experience showed low use of this [8].

(c) Information Accessibility limited to be in patients presence was also highlighted as a concern by some healthcare providers in pharmacy [40].

\subsubsection{Awareness and Knowledge}

Lack of awareness and limited knowledge about MyHR was raised as an issue contributing to slow uptake. A national survey found that healthcare providers and consumers had low awareness and knowledge about MyHR. There were only $62 \%$ respondents thought that it could help in better quality care but only $50 \%$ were ready to sign up. This low level was justified as the survey was conducted before the launch in 2012 [33]. A survey conducted after the system launch in 2012 also indicated that only $18 \%$ consumers were aware of MyHR out of 98 respondents [38]. In another study, the survey was conducted in a rural area of Victoria during 2013 which again noted that there was low awareness in the community about the system through newspapers and word to mouth but only 5 respondents had registered, whereas 67 did not due to lack of sufficient knowledge [52]. A more recent study found that Australian consumers and healthcare providers generally were negative about MyHR due to uncertainty stemmed into unawareness of the system operations [37].

As part of change and adoption program, there were advertising campaigns to promote MyHR in late 2013 that increased the number of registered consumers [8]. But the campaign was noted high level and not relating to consumers' needs [52]. Consumers were interested to learn about the system and availed the offered opportunities when possible [42, 59]. Healthcare providers training programs were also conducted through change and adoption program training partners, RACGP.

\subsubsection{Ethical Considerations}

MyHR enabled collection of vast amount of sensitive information, raising discussions about secondary use/research of collected data and ethical issues around it [35], however, these ethical issues in MyHR remained overshadowed by technical and business requirements related matters [15]. Important ethical considerations for MyHR were identified in international and expert informants' studies [15, 26].

(a) Issues of equity arising in personal control level. Although personal control to consumers was expected to translate into better health outcomes, the experience with GoogleHealth did not reflect this. The level of personal control with MyHR might result in not receiving 'trustworthy' regard by 
healthcare professionals. Consumers with high pressure factors like social instability, poverty, major family stress, serious disability/cognitive capacity and limited health literacy could potentially result inequalities with access or no access to the health record [15].

(b) Who benefits and should pay for it. This was a question for long term MyHR funding requiring reflection on the cost, benefit and success of MyHR. Generally, there was no clear definition of success or failure when it comes to measuring impact of EHRs. An investment model developed for Australia's eHealth initiative was questioned by some if it was appropriate to measure success of MyHR with justice and equity in addition to economics. At present, health records management responsibility falls on healthcare providers; there were arguments that when MyHR was for consumers why the bulk of cost is expected to be covered by healthcare providers [15].

(c) Legitimate uses of MyHR data and Research Ethics. While MyHR data primary use was for patient care, there were potentially secondary uses of this information for policy, research, audit and public health. Limited research was available about consumers perspective in this aspect, considering it legitimate use and highlighting concerns about information security, privacy, research integrity and consents. With lack of debate and transparency on the secondary uses of MyHR patient data, questions were raised about illegitimate uses, meaning its exposure beyond clinical circle of care, insurance companies, employers, police or the government, resulting in discrimination or disadvantage position $[15,26,60]$.

(d) Privacy and confidentially. Despite of strong support for national EHR [61], Australian consumers were generally found particular about their privacy and confidentiality of their health data in MyHR [15, 22, 26, 37]. 'What goes in their record', 'who have access to it' and 'when it is accessed' were important concerns for consumers and considered as one of the perceived risks to the uptake of this system [35]. According to a survey, the consumers had perception that potential of privacy breaches in electronic format was more than paper-based records. It was argued that this was due to lack of education and knowledge [33].

(e) Opting-in to the MyHR was believed as consumers consenting to healthcare providers and reporting users for primary and secondary use of health data. This was an unclear aspect of the system, resulting in privacy concerns [15]. Although audit log function enabled checking of who accessed the health record, consumers were unsure about any potential unauthorized access that does not get logged. There were also concerns about the information deleted by consumers that remain in the system even they remove their participation [52].

(f) Stakeholders Needs highlighted by $[15,26]$ explained three different variations: (i) Children and Adolescents that gets registered with MyHR at young age would seem to encounter disempowering issues such as certain health matters that they might not want to share with parents, or any conditions present in childhood but does not apply when they reaches adulthood. They would have different needs from MyHR to enable their personal control, which some expert believed was not significant while others argued to be considerate about it. (ii) Conflicting Interests could occur with consumers values of privacy and need of information transparency by healthcare professional as well as researchers/policy makers for performance measurement, service analysis and planning. (iii) Cultural Diversity of Australian society could also pose some ethical issues, such as access to records of wife/husband or child in some cultures, Australians distrust of government, doctors' resistance to change, mistrust of big databases with government, insurer and employers and the uncertainty around computers/internet among elderly.

\subsubsection{Impact of Policy, Economics and Legislations}

Government policies influence the development and implementation of national systems, MyHR was no different. Insufficient political commitments could lead to system failure. A review report by Boston Consulting Group revealed MyHR project face problems of inadequate stakeholder management and regional cooperation [62]. Although MyHR implementation had been supported by Australian political labour and liberal parties but there were arguments about the approach [7]. This resulted in MyHR 2013 review when liberal party came into power, consuming a year before recommendations commenced in action [56].

The uncertainty of Australian economy with unstable commodity market affects government's financial capability to continue support of this long and expensive project. This was particularly important when a system like MyHR was expected to show its real benefits in ten years' time [7] and require continued funding [15].

In addition, MyHR legislation and regulations also raised some medico-legal concerns, especially in areas like participation agreement, information access, fine and penalties related to MyHR administration [7, 29, 35]. During the first couple of years after MyHR launch, there was no or limited professional indemnity insurance for 
healthcare providers towards these legal risks, resulting in opt-out MyHR participation [52, 63].

\subsubsection{MyHR Comparison Worldwide}

Many countries were found in process of implementing EHR solutions at the national level to facilitate patient journey and healthcare delivery. Their approach and its success rate was variant [6]. It was generally considered to be a challenging venture, where countries were acting upon without experiences or reference to lessons learnt from elsewhere worldwide. Although each of such national implementations had its own characteristics of target community, unique expectations, healthcare system, economic status and legal framework. There were no set of common polices and guidelines [28] but by comparing elsewhere important observations can be made in aspects of patient data ownership and consent, privacy issues and data de-identifications [64].

(a) Middle-out Approach. The Australia's MyHR system was informed by a combination of 'topdown' and 'bottom-up' national implementation for its development and associated infrastructure [65], putting itself in 'middle-out' approach. In a topdown approach (UK), government replaced existing systems to establish a centrally stored health record. A bottom-up (US) approach involved healthcare agencies holding health records digitally to share as diverse local systems gets integrated over time. Middle-out approach (Australia) was the one where instead of government implementation, focus was set on standards with nationally agreed interoperability standards and goals that gets delivered through healthcare providers [34].

(b) Highlighted Models. Literature demonstrated progress of UK, US, New Zealand, Canada, Denmark, Singapore and China towards national implementation like MyHR [6, 28, 38, 66, 67]. Highlights included here are those models adapted in Denmark, UK and US.

(i) Denmark's National eHealth Portal was considered a shining example which provided an access point to healthcare services for citizens and healthcare professionals. Citizens could login to a personal web space to book appointments with medical practitioners, order medications and renew prescriptions, review medication records and health data and communicate with healthcare authorities. Healthcare professionals were also able to log on to the portal that gave a framework for communication about specific patients, access excerpts of records from hospitals and access other information, such as laboratory results and data from electronic patient records [6]. All
Danish hospital clinicians, $98 \%$ of primary care clinicians, and all pharmacists had access to this centralized database, which was also accessible to consumers for their own records [28].

(ii) The United Kingdom's National eHealth initiative, where National health services (NHS) first commenced a Personal Demographic Service (PDS) comprising demographic information such as name, address, date of birth, NHS number, then introduced smartcards for clinicians to access PDS followed by launch of Summary Care Record (SCR) and HealthSpace. SCR is based on opt-out model, holds individuals' clinical information, initially drawn from general practitioner held electronic records, such as allergies, medicines, adverse reaction information etc. and was provided as electronic summary to authorized healthcare providers. HealthSpace was personal organizer (accessible online) for people to enter their health data and plan health appointments. However, reports indicated most expected benefits of better, safer, efficient, equitable care and greater patient satisfaction would not be achieved from SCR or HealthSpace $[6,15,28]$.

(iii) In the United States, national eHealth plan included investing and mandating for medical practitioners and hospitals to adopt electronic record keeping and ordering system that enabled access to health records to its patients $[22,28]$. Healthcare providers were supported with financial incentives for the meaningful use of such technology [6].

(c) Critical success factors of national implementations globally were compared with MyHR in a study by $[28,62]$, it identified four critical areas for consideration:

(i) Demonstration of benefits and funding. Clinicians and consumers did not see value in the present state of MyHR as they lack knowledge about its expectations and perceived benefits. Benefit realization is vital for adoption, like approach adapted by Denmark and Canada where high emphasis was placed on clinical engagement about health record content and standards.

(ii) Acceptance and change management. This refers to areas like poor convincing of clinicians, difficulty in implementing necessary organizational changes, health policy goals and selected implementation strategies. For MyHR implementation healthcare providers were given list of requirements to fulfil, which were believed to be complicated and tedious. The 
communication of these requirements was through checklist to healthcare providers that probably made the message conveying more difficult. If they were engaged in awareness programmes and workshop like Singapore's approach, compliance could have better outcomes. Patient engagement model of opt-in was also noted as an area to consider as medical community support critical mass of people registered like that of UK's SCR.

(iii) Technology, infrastructure and Human Resources. Australia was believed to take correct and regulated approach towards technology than UK and US as clinical software required by healthcare providers must pass the Conformance, Compliance and Accreditation (CCA) certificate before it can be made available to clinicians. Government incentive scheme (ePIP) to implement, train and use of MyHR need also to be continue for healthcare providers, like Denmark and Singapore. Unavailability of skilled human resources for healthcare IT specialists was also associated with problems in other countries like UK, Canada and Denmark who actioned useful measures to overcome it and noted as an area for Australia to consider.

(iv) Economic and Legal Perspective. Proper economical balance with justifiable return on investment (ROI) is essential in such initiatives where ROI must be measurable and reflect expectation. Canada was an example where they measure its ROI through patient safety, quality and effectiveness of healthcare delivery. In terms of legal and regulatory foundations, Australia seem to be on track with its privacy laws, unlike US.

\section{Conclusion and Future Research}

This paper has demonstrated a holistic view of MyHR implementation, its evaluation and users' perspectives. There is information about adoption of MyHR among GPs, and its impact in medical practice morals, patient workflow and clinician time. However, the extent and details of this impact in general practices as organization, its work practices/workflows and the perspectives of involved is yet to be explored. In keeping with the international literature, assessing benefits remains difficult in health systems with many moving parts, and when the timelines for adoption, and therefore population-based benefits are measured in tens of years. This review shows the problems of usability and workflow to underpin adoption, whilst highlighting the general acceptance that shared health information is the way forward. To achieve big picture benefits, care must be taken in the details.

In future work, research conceptual framework will be developed for MyHR evaluation based on user acceptance factors. Participant general practices will be engaged in data collection. The MyHR implementers and GPs will be interviewed. Observations of MyHR interactions during $\mathrm{GP} /$ patient consultation will be made. A survey will be conducted to gather views and experiences of MyHR users in participant organizations and other general practices of Victoria. All the collected data will be analyzed in light of the proposed conceptual model to explore and evaluate system adoption. Challenges will be identified and strategies to address them will be suggested, therefore, offering its contribution to the knowledgebase.

\section{References}

[1] E. Murray et al., "Evaluating digital health interventions: key questions and approaches," ed: Elsevier, 2016.

[2] N. Wickramasinghe and J. Schaffer, "Realizing value driven e-health solutions," Report for IBM. Washington DC, 2010.

[3] Australia Digital Health Agency, "Australia's National Digital Health strategy 2018-2022," 2017.

[4] (2008). Australian National E-Health Strategy 2008. Available:

http://www.health.gov.au/internet/main/publishing. nsf/Content/National+Ehealth + Strategy

[5] K. Garrety, I. McLoughlin, R. Wilson, G. Zelle, and M. Martin, "National electronic health records and the digital disruption of moral orders," (in English), Social Science \& Medicine, vol. 101, p. 70, Jan 20142014.

[6] R. Jolly, "The ehealth revolution - easier said than done," 17-11-2011 2011, Available: http://www.aph.gov.au/About_Parliament/Parliame ntary Departments/Parliamentary Library/pubs/rp/r p1112/12rp03.

[7] J. Xu, X. Gao, G. Sorwar, and P. Croll, "Current Status, Challenges, and Outlook of E-Health Record Systems in Australia," in Knowledge Engineering and Management: Springer, 2014, pp. 683-692.

[8] M. B. Christopher Pearce, "A personally controlled electronic health record for Australia," 2014.

[9] I. Muhammad, S. Y. Teoh, and N. Wickramasinghe, "Why using actor network theory (ANT) can help to understand the personally controlled electronic health record (PCEHR) in Australia," International Journal of Actor-Network Theory and Technological Innovation (IJANTTI), vol. 4, no. 2, pp. 44-60, 2012.

[10] Australian Bureau of Statistics, "Patient Experiences in Australia: Summary of Findings, 2014-15," 2015, Available: http://www.abs.gov.au/AUSSTATS/abs@.nsf/Detai lsPage/4839.02014-15?OpenDocument. 
[11] E. Willis, L. Reynolds, and H. Keleher, Understanding the Australian Health System, 2nd ed. 2014.

[12] Department of Health and Ageing, "The readiness of Australian General Practitioners for the eHealth record," 2011.

[13] T. N. Wade, Annapurna GP change management strategy : engagement with general practice (no. Accessed from https://nla.gov.au/nla.catvn3944689). Adelaide: HealthConnect SA, 2006.

[14] P. Naismith, "eHorizons: The PCEHR future is here," The Australian Journal of Pharmacy, vol. 93 no. 1106, pp. 62-63, Jul 20122012.

[15] M. Spriggs, M. V. Arnold, C. M. Pearce, and C. Fry, "Ethical questions must be considered for electronic health records," Journal of Medical Ethics, vol. 38, no. 9, pp. 535-539, 09// 2012.

[16] C. Pearce, J. Bartlett, A. McLeod, P. Eustace, R. Amos, and M. Shearer, "Effectiveness of local support for the adoption of a national programme-a descriptive study," Informatics in Primary Care, Prespectives based Evaluation vol. 21, no. 4, pp. 171-178, 2014

[17] H. Almond, E. Cummings, and P. Turner, "Using community based participatory research as a method for investigating electronic health records," Driving Quality in Informatics: Fulfilling the Promise, Framework based Evaluation vol. 208, pp. 40-4, 20152015

[18] M. Najaftorkaman, A. H. Ghapanchi, and A. TalaeiKhoei, "Effectiveness of a Personally Controlled Electronic Health Record Intervention in Older Adults with Chronic Disease," presented at the The 26th Australasian Conference on Information Systems 2015, Adelaide, 2015. Available:

https://acis2015.unisa.edu.au/wpcontent/uploads/2015/11/ACIS 2015 paper 14.pdf

[19] W. Bandara, E. Furtmueller, E. Gorbacheva, S. Miskon, and J. Beekhuyzen, "Achieving Rigor in Literature Reviews: Insights from Qualitative Data Analysis and Tool-Support," Communications of the Association for Information systems, vol. 34, 2015.

[20] C. Pearce, C. Macdougall, M. Bainbridge, and J. Davidson, "Ensuring Clinical Utility and Function in a Large Scale National Project in Australia by Embedding Clinical Informatics into Design," in "Medinfo 2013: Proceedings of the 14th World Congress on Medical and Health Informatics, Pts 1 and $2, " 0926-9630$

978-1-61499-289-9; 978-1-61499-288-2, 2013, vol. 192 Available: $<$ Go to ISI $>$ ://WOS:000341021700006.

[21] L. Oke. (2014, Oct 2014) Remember the vital allies of good healthcare. Health Voices. 12-13. Available:

http://search.informit.com.au/documentSummary;d $\mathrm{n}=761856111974227 ; \mathrm{res}=$ IELHEA

[22] P. Kerai, P. Wood, and M. Martin, "A pilot study on the views of elderly regional Australians of personally controlled electronic health records," International Journal of Medical Informatics,
Prespectives based Evaluation vol. 83, no. 3, pp 201-209, Mar 2014

[23] C. Spiranovic, A. Matthews, J. Scanlan, and K. C. Kirkby, "Personally controlled electronic health records in Australia : Challenges in communication of mental health information," (in English), Advances in Mental Health, vol. 12, no. 2, pp. 147153, Aug 20142014.

[24] K. van Dooren, N. Lennox, and M. Stewart, "Improving access to electronic health records for people with intellectual disability: A qualitative study," Australian Journal of Primary Health, Prespectives based Evaluation vol. 19, no. 4, pp. 336-342, 20132013.

[25] M. Frommer, "Electronic health records : Taking control of your e- health future," HIV Australia, vol. 10, no. 1, pp. 21-24, Jun 20122012.

[26] C. L. Fry, M. Spriggs, M. Arnold, and C. Pearce, "Unresolved Ethical Challenges for the Australian Personally Controlled Electronic Health Record (PCEHR) System: Key Informant Interview Findings," AJOB Empirical Bioethics, Prespectives based Evaluation vol. 5, no. 4, pp. 30-36, 2014.

[27] J. Halton, "E-Health lines open," in "Public Administration Today," 1832-0066, Apr-Jun 2013 2013.

[28] R. Gajanayake, T. Sahama, and R. Iannella, "Ehealth in Australia and elsewhere: a comparison and lessons for the near future," Studies in health technology and informatics, vol. 188, pp. 26-32, 2013.

[29] AMA. (2013, May 2013) PCEHR update. Medicus. 7. Available:

http://search.informit.com.au/documentSummary; d $\underline{n}=317955577564801 ;$ res $=$ IELHEA

[30] G. Robertson. (2014, Oct 2014) Bringing diagnostic reports into the eHealth record. Health Voices. 2021. Available: http://search.informit.com.au/documentSummary;d $\underline{n}=761949276830518 ;$ res $=$ IELHEA

[31] T. Koh, "New PIP requirement betrays blinkered approach," (in English), Medicus, vol. 56, no. 1, p. 33, Feb 20162016.

[32] (2013). Review of Pesonally Controlled Electronic Health Record (PCEHR)

[33] E. C. Lehnbom, J. E. Brien, and A. J. McLachlan, "Knowledge and attitudes regarding the personally controlled electronic health record: an Australian national survey," Internal Medicine Journal, Prespectives based Evaluation vol. 44, no. 4, pp. 406-409, Apr 2014.

[34] L. Andrews, R. Gajanayake, and T. Sahama, "The Australian general public's perceptions of having a personally controlled electronic health record (PCEHR)," International Journal of Medical Informatics, Framework based Evaluation vol. 83, no. 12, pp. 889-900, Dec 2014.

[35] B. L. Srur and S. Drew, "Challenges in designing a successful e-health system for Australia," in Information Technology in Medicine and Education 
(ITME), 2012 International Symposium on, 2012, vol. 1 , pp. $480-484$.

[36] T. Pullen, "Whether the factors of relative advantage, compatibility and complexity influence care providers' willingness to adopt shared electronic health records," Degree of Doctor of Philosophy Framework based Evaluation, University of Southern Queensland, 2012.

[37] E. C. Lehnbom, H. E. Douglas, and M. A. B. Makeham, "Positive beliefs and privacy concerns shape the future for the Personally Controlled Electronic Health Record," Internal Medicine Journal, Framework based Evaluation vol. 46, no. 1, pp. 108-111, Jan 2016.

[38] I. Muhammad, "The Personally Controlled Electronic Health Record (PCEHR): An Evaluation," Doctor of Philosophy Framework based Evaluation, School of Business IT and Logistics, RMIT, 2015.

[39] J. A. Quinlivan, S. Lyons, and R. W. Petersen, "Attitudes of Pregnant Women Towards Personally Controlled Electronic, Hospital-Held, and PatientHeld Medical Record Systems: A Survey Study," Telemedicine and E-Health, Prespectives based Evaluation vol. 20, no. 9, pp. 810-815, Sep 2014.

[40] A. Mooranian, L. Emmerton, and L. Hattingh, "The introduction of the national e-health record into Australian community pharmacy practice: pharmacists' perceptions," International Journal of Pharmacy Practice, Prespectives based Evaluation vol. 21, no. 6, pp. 405-412, 12// 2013.

[41] E. Lehnbom, A. McLachlan, and J.-a. Brien, "A qualitative study of Australians' opinions about personally controlled electronic health records," Studies in Health Technology \& Informatics, Prespectives based Evaluation vol. 178, pp. 105-110 $6 \mathrm{p}, 2012$.

[42] H. Almond, E. Cummings, and P. Turner, "Avoiding Failure for Australia's Digital Health Record: The Findings from a Rural E-Health Participatory Research Project," in Digital Health Innovation for Consumers, Clinicians, Connectivity and Community: Selected Papers from the 24th Australian National Health Informatics Conference (HIC 2016), 2016, vol. 227, p. 8: IOS Press.

[43] NEHTA, "Draft Concept of Operations: Relating to the introduction of a Personally Controlled Electronic Health Record System," 2011, Available: http://content.webarchive.nla.gov.au/gov/wayback/2 0130329000623/http:/www.yourhealth.gov.au/inter net/yourhealth/publishing.nsf/Content/PCEHRSIntro-toc/\$File/PCEHR-Concept-of-Operations-1-05.pdf.

[44] T. Smith, "Bloom fading from e-health golden wattle," (in English), Canadian Medical Association. Journal, vol. 184, no. 9, pp. E459-60, 2012 Jun 122012.

[45] C. Pettiford, "Letter to the Editor: Personallycontrolled electronic health records have potential to improve reporting on quality and safety in
Australia," Health Information Management Journal, vol. 41, no. 1, pp. 35-36 2p, 2012.

[46] D. Grunwell and T. Sahama, "Information accountability and Health Big Data Analytics: A consent-based model," in 2015 17th International Conference on E-health Networking, Application \& Services (HealthCom), 2015, pp. 195-199.

B. Fisher, V. Bhavnani, and M. Winfield, "How patients use access to their full health records: a qualitative study of patients in general practice," Journal of the Royal Society of Medicine, vol. 102, no. 12, pp. 539-544, 2009.

[48] A. Black, T. Sahama, and R. Gajanayake, "eHealthas-a-Service (eHaaS): a data-driven decision making approach in Australian context," Studies in health technology and informatics, vol. 205, pp. 915-9, 2014.

[49] B. Host, "eHealth," Medicus, vol. 52, no. 3, p. 22, Apr 20122012.

[50] A. Rollins, "Forcing GPs to adopt half-baked ehealth record a dud idea: AMA," (in English), Australian Medicine, vol. 27, no. 10A, p. 15, 03 Nov 20152015.

[51] R. Gajanayake, T. Sahama, and R. Iannella, "The role of perceived usefulness and attitude on electronic health record acceptance," in e-Health Networking, Applications \& Services (Healthcom), 2013 IEEE 15th International Conference on, 2014, pp. 388-393.

[52] U. Raza Khan, "Study of eHealth in Australia and its adoption in Regional Victoria (Australia)," MSc Business Strategic and Information Systems, Business School, University of Hertfordshire, 2013.

[53] A. S. Gosling and J. I. Westbrook, "Allied health professionals' use of online evidence: a survey of 790 staff working in the Australian public hospital system," International journal of medical informatics, vol. 73, no. 4, pp. 391-401, 2004.

[54] J. McIlwraith, "PCEHR : Does the primacy of privacy come at a cost?," Precedent (Sydney, N.S.W.), no. 108, pp. 30-34, Jan/Feb 20122012.

[55] A. Pharmacist. (2014, Jan 2014) Greater access to electronic medical records. Australian Pharmacist. 26.

[56] A. Rollins, "\$1bn e- health record system shunned," (in English), Australian Medicine, vol. 27, no. 2A, p. 10, 03 Mar 20152015.

[57] A. C. Flannigan, "Health law and privacy: Health records privacy: Contemporary issues, complaints and claims," (in English), LSJ: Law Society of NSW Journal, vol. 2, no. 6, pp. 80-81, Jul 20152015.

[58] E. Hossack, "Australia's national health recordputting the pceher into perspective," (in English), Medicus, vol. 55, no. 8, pp. 33-34, Sep 20152015.

[59] U. R. Khan, T. Zia, and K. Perera, "An exploratory study of the role of eHealth in Healthy Ageing," 2016.

[60] S. Torvaldsen, "Your practice data - goldmine, headache, or public health bonus (or all of the above)?," (in English), Medicus, vol. 55, no. 8, pp. 26-27, Sep 20152015. 
[61] J. Xu, X. Gao, G. Sorwar, and P. Croll, "Implementation of E-health Record Systems in Australia," The International Technology Management Review, vol. 3, no. 2, pp. 92-104, 2013.

[62] E. Deutsch, G. Duftschmid, and W. Dorda, "Critical areas of national electronic health record programsIs our focus correct?," International Journal of Medical Informatics, vol. 79, no. 3, pp. 211-222, Mar 2010.

[63] E. Kruys. (2013, Sept 2013) GP matters: The PCEHR : Moving forward. Medicus. 6-7. Available: http://search.informit.com.au/documentSummary; $\mathrm{n}=563016415552647 ; \mathrm{res}=$ IELHEA

[64] B. B. Arnold and W. Bonython. (2014, Oct 2014) Should we stripmine your eHealth data? Health Voices. 18-19. Available: http://search.informit.com.au/documentSummary; d $\mathrm{n}=761930643859260 ;$ res=IELHEA

[65] E. Cummings et al., "The Cradle Coast personally controlled electronic health record evaluation research," Studies in Health Technology \& Informatics, vol. 178, pp. 14-19 6p, 2012.

[66] P. Haddad, J. L. Schaffer, and N. Wickramasinghe, "Evaluating Business Value of IT in Healthcare: Three Clinical Practices from Australia and the US," Studies in health technology and informatics, vol. 216, pp. 183-7, 2015.

[67] N. Tavakoli, S. S. Isfahani, Z. Piri, and A. Amini, "Patient access to electronic health record: a comparative study on laws, policies and procedures in selected countries," Medical archives (Sarajevo, Bosnia and Herzegovina), vol. 67, no. 1, pp. 63-7, 20132013. 